\title{
Clinical and Etiological Profile of an Exudative Pleural Effusion in a Tertiary Care Center
}

\author{
S. Laxma Reddy, K. Varaprasad, Narendrakumar Narahari, K. Bhaskar, G. Rajashekar Varma, G. K. Paramjyothi \\ Department of Pulmonary Medicine, Nizam's Institute of Medical Sciences, Hyderabad, Telangana, India
}

\section{Abstract}

Background: Pleural effusion is common clinical entity in day-to-day clinical practice. There are various etiologies for pleural effusion. Among those tubercular pleural effusion, parapneumonic effusion, malignant effusion, and congestive heart failure were the most common causes of pleural effusion. Here, we have done a retrospective study to see the etiology of pleural effusion in our tertiary care center. Patients and Methods: This retrospective study conducted in a tertiary care center over 1 year period. A total of 63 patients were included in this study after verifying in patient records of all patients who were admitted with exudative pleural effusion. The demographic data collected and complete history was obtained. Investigations such as complete hemogram, random blood sugar; renal function tests, serum proteins, chest x-ray, and pleural fluid analysis and investigations such as ultrasonogram of the chest and abdomen, echocardiogram, computed tomography scan of chest, fine-needle aspiration cytology, and pleural biopsy reports (if done) were collected. Results: Among the study participants, 40 were male and 23 were female patients with male-to-female ratio of 1.7:1. Mean age of the study population was $48.8 \pm 18.7$ years. The most common presenting symptom was dyspnea $(84 \%)$ followed by cough $(80 \%)$, fever $(65 \%)$, and chest pain $(43 \%)$. The most frequent cause of pleural effusion was tuberculosis in $38 \%$ of patients, followed by parapneumonic effusion (28.5\%) and malignant pleural effusion (22.2\%). Three patients had chylothorax, two patients had pancreatic pleural effusion and the diagnosis was unknown in two patients. Mean \pm standard deviation (SD) adenosine deaminase (ADA) value of the study population was $45.3 \pm 28.1$. Mean \pm SD of ADA values in tuberculous, parapneumonic, and malignant pleural effusion was $54.5 \pm 16.8,65.2 \pm 30.7$, and 18.2 \pm 11.0 , respectively. Conclusions: Tuberculosis is one of the common causes of exudative effusions along with parapneumonic effusions and malignancy. Pleural fluid ADA levels are highly sensitive with good specificity for the diagnosis of etiology of tubercular effusions. However in view of high levels of ADA in pleural fluid in parapneumonic effusions also, other measures such as clinical evaluation, lymphocyte to neutrophil ratio, and glucose levels are necessary to separate both these entities.

Keywords: Adenosine deaminase, pleural effusion, tuberculosis

\section{INTRODUCTION}

Pleural effusion results from either excess fluid accumulation in pleural space or decreased absorption by pleural lymphatics. ${ }^{[1]}$ Normally, $0.13 \mathrm{~mL} / \mathrm{kg}$ of body weight of fluid is present in pleural space. This small amount of fluid acts as a lubricant to allow the smooth sliding of parietal and visceral pleura during respiration. ${ }^{[2]}$ Normal amount of fluid is maintained by the balance between hydrostatic, oncotic pressure of pleural capillaries and intrapleural pressure, oncotic pressure of pleural fluid. Any imbalance of the above mechanism will lead to excess fluid accumulation in pleural space. ${ }^{[3]}$ Pleural effusions were either transudative or exudative, Light's criteria ${ }^{[4]}$ are commonly used to differentiate exudative effusion from transudative effusion. Pleural fluid is exudative if it meets any one of the following

\begin{tabular}{|l|l|}
\hline \multicolumn{2}{|c|}{ Access this article online } \\
\hline Quick Response Code: & Website: \\
& www.ijrconline.org \\
\cline { 2 - 2 } & \\
&
\end{tabular}

criteria-pleural fluid protein/serum protein ratio $>0.5$ or pleural fluid lactate dehydrogenase $(\mathrm{LDH})$ /serum $\mathrm{LDH}$ ratio $>0.6$ or pleural fluid LDH level greater than two-thirds the upper limit. Congestive heart failure is the most common condition that produce transudative pleural effusion followed by hepatic hydrothorax. Nephrotic syndrome, hypoproteinemia are some other common causes. ${ }^{[5]}$ Common causes of exudative effusion include tuberculosis, parapneumonic effusion, viral infections, and malignancy. ${ }^{[6]}$ Other causes include hypothyroidism,

Address for correspondence: Dr. K. Bhaskar, Department of Pulmonary Medicine, Nizam's Institute of Medical Sciences, Panjagutta, Hyderabad, Telangana - 500 082, India. E-mail: bhaskarsr999@gmail.com

This is an open access journal, and articles are distributed under the terms of the Creative Commons Attribution-NonCommercial-ShareAlike 4.0 License, which allows others to remix, tweak, and build upon the work non-commercially, as long as appropriate credit is given and the new creations are licensed under the identical terms.

For reprints contact: reprints@medknow.com

How to cite this article: Reddy SL, Varaprasad K, Narahari N, Bhaskar K, Varma GR, Paramjyothi GK. Clinical and etiological profile of an exudative pleural effusion in a tertiary care center. Indian J Respir Care 2019;8:22-6. 
pulmonary embolism with infarction, connective tissue disorders, pancreatitis, esophageal rupture (Boerhaave's syndrome), collagen vascular disorders, chylothorax, and hemothorax.

On chest radiograph, pleural effusion is usually seen as an area of homogeneous opacity with ill-defined margins with tracking along the lateral chest wall. If the fluid is small (up to $50 \mathrm{~mL}$ ) lateral chest radiograph is better than posteroanterior chest X-ray. ${ }^{[7]}$ Computed tomography (CT) is usually required to quantify the fluid and to identify loculations along with the presence of parenchymal and mediastinal abnormalities which may be missed on the standard radiograph. Ultrasonography chest recently gained more importance in diagnosis of pleural effusion and it is more sensitive than chest radiograph. It is safe, there is no radiation and has the benefit of repeatability. ${ }^{[8]}$ It can be used to identify the loculations and septations in pleural cavity. It can also be used to guide aspiration and choose site of insertion of intercostal tube.

A provisional diagnosis is usually made in over $90 \%$ of patients based on clinical features and pleural fluid analysis. ${ }^{[9]}$ However, definitive diagnosis is usually made by either identification of malignant cells, pleural biopsy or identification of a specific organism in pleural fluid. Thoracentesis is indicated in all patients with suspicion of exudative pleural effusion with thickness $>10 \mathrm{~mm}$ in lateral chest radiograph, ultrasound, or in CT scan. The first step is to differentiate between transudative from exudative pleural effusion. All the exudative effusions should be observed for color and odor. Laboratory tests that are performed to analyze the pleural fluid include total leucocyte count, differential count, and biochemical tests such as proteins, glucose, LDH, amylase, microbiological examinations such as AFB stain, Gram stain, culture sensitivity, adenosine deaminase (ADA) levels, and cytopathology. Additional investigations such as triglycerides and chylomicrons are requested depending on the clinical dilemma. Closed pleural biopsy is indicated if there is suspicion of tuberculosis and ADA levels were low. Thoracoscopy is a highly sensitive tool for evaluation of undiagnosed exudative pleural effusions. ${ }^{[10]}$ Two diagnoses that commonly obtained with thoracoscopic pleural biopsy are tuberculosis and malignancy.

This is a retrospective study conducted to look at the etiology of exudative pleural effusion in a tertiary care center.

\section{Patients and Methods}

This study was performed in the Department of Pulmonary Medicine, Nizam's Institute of Medical Sciences, a tertiary care center in Hyderabad, Telangana. The main aim of this study was to assess the clinical and etiological profile of exudative pleural effusions. This was a retrospective study which included all in-patients admitted with exudative pleural effusion from January 2017 to December 2017. Totally 63 patients with exudative pleural effusion were recruited for this study. All patients with transudative pleural effusions were excluded.

The demographic data collected included age, sex, and address. A detailed history including chief complaints, history of presenting illness, significant history including comorbidities was obtained. Investigations obtained included complete hemogram, random blood sugar; renal function tests, thyroid function tests, serum proteins, chest X-ray, and pleural fluid analysis, ultrasonogram of the chest and abdomen, echocardiogram, CT scan of chest, fine-needle aspiration cytology and pleural biopsy reports (if done).

All the data were entered into Microsoft Excel and Statistical Package for the Social Sciences (SPSS, Chicago, U.S) version 20.0 was used to analyze the data. All data were analyzed for frequency distribution, and results were given in mean and standard deviation (SD). Analysis of variance and $t$-test were used to test the significance in between group variables. $P<$ 0.05 was considered as statistically significant.

\section{RESULTS}

This retrospective study was conducted in a tertiary care hospital in Hyderabad. Totally 63 patients were recruited during 1 year period.

Among the study participants, 40 were male and 23 were female with male-to-female ratio of 1.7:1.

Age ranged from 14 to 85 years. Mean age of the study population was $48.8 \pm 18.7$ years. Majority of the study population (63.4\%) were between 20 and 60 years of age. Only five patients were below 20 years.

The most common presenting symptom was dyspnea (84\%) followed by cough (80\%), fever (65\%), and chest pain (43\%). Loss of weight and loss of appetite were present in $27 \%$ of the patients. Hoarseness of voice was present in two patients and jaundice, hemoptysis, and pedal edema; were present in one patient each.

Majority of the study population had 3-4 weeks duration of symptoms before coming to our institution. Mean $\pm \mathrm{SD}$ duration of symptoms was $3.82 \pm 2.8$ weeks. Very few participants had symptoms of $<1$ week duration.

The most frequent etiology of pleural effusion was tuberculosis in $38 \%$ of patients, followed by parapneumonic effusion (28.5\%), malignant pleural effusion (22.2\%). Three patients had chylothorax, two patients had pancreatic pleural effusion, and the diagnosis was unknown in two patients.

All the patients with tuberculous pleural effusion had ADA levels above the cut-off value $(30 \mathrm{U} / \mathrm{L})$ with mean $\pm \mathrm{SD}$ value of $54.50 \pm 16.8$ whereas, $88 \%$ of patients with malignant effusion had ADA levels below the cut-off value (30 U/L). Only two patients with malignant effusion had ADA value above cut-off value $(P<0.01)$.

\section{Discussion}

This retrospective study was conducted in a tertiary care hospital in Hyderabad. Totally 63 patients were included during 1 year period. Among the study participants, 40 were male 
and 23 were female patients with a male-to-female ratio was 1.7:1 [Figure 1]. Age is ranged between 14 and 85 years. Mean age of the study population was $48.8 \pm 18.7$. Majority of the study population (63.4\%) was between 20 and 60 years of age because people of this age group were physically active and are exposed to occupation hazards, smoking, and infections. Only five patients were below 20 years [Table 1]. A study in Qatar by Khan et al. ${ }^{[11]}$ showed that the mean age of the study population was $47.4 \pm 18.2$ years and male-to-female ratio was 3:1. Similarly in a study by Arya Shashikant and Archana ${ }^{[12]}$ from India showed that the mean age of their 100 study population was 38.10 years with most of the study population were between 21 and 60 years of age and male-to-female ratio was 2.3:1. Another study from India by Raghavan et al. ${ }^{[13]}$ included 100 patients of which majority of male patients with an age group of $30-60$ years with a mean of $46.49 \pm 13.5$ years.

In our study, most common presenting symptom was dyspnea (84\%) followed by cough (80\%), fever (65\%), chest pain $(43 \%)$. Loss of weight and loss of appetite was present in $27 \%$ of the patients. Hoarseness of voice was present in two patients and jaundice, hemoptysis; pedal edema was present each in one patient [Table 2]. Similar study by Al-Alusi ${ }^{[14]}$ included 100 patients in their study, of which the most common symptoms were dyspnea $(87 \%)$, cough $(86 \%)$, fever $(79 \%)$ followed by chest pain (67\%). In a similar study done by Mbata Godwin et al., ${ }^{[15]}$ the major symptoms were cough in $156(78.4 \%)$ patients followed by chest pain in $142(71.4 \%)$ and dyspnea in $130(65.3 \%)$. Desalew et al. ${ }^{[16]}$ in their study of 110 patients, cough fever, and weight loss were present in $90 \%, 77.3 \%$, and $77.3 \%$ of cases, respectively. Majority of the study population had 3-4 weeks duration of symptoms before coming to our institution. Mean \pm SD duration of symptoms $3.82 \pm 2.8$ weeks. Very few participants had symptoms of $<1$ week duration [Figure 2].

\section{Table 1: Age wise distribution of study population}

\begin{tabular}{lcc}
\hline Age group & Number & Percentage \\
\hline$<20$ & 5 & $8.0 \%$ \\
$20-39$ & 16 & $25.0 \%$ \\
$40-60$ & 24 & $38.0 \%$ \\
$>60$ & 18 & $29.0 \%$ \\
\hline
\end{tabular}

\section{Table 2: Symptomology of study population}

\begin{tabular}{lcc}
\hline Symptom & Frequency & Percentage \\
\hline Dyspnea & 53 & $84.0 \%$ \\
Cough & 51 & $80.0 \%$ \\
Fever & 41 & $65.0 \%$ \\
Chest pain & 27 & $43.0 \%$ \\
Loss of appetite & 17 & $27.0 \%$ \\
Loss of weight & 17 & $27.0 \%$ \\
Hoarseness of voice & 2 & $3.0 \%$ \\
Jaundice & 1 & $1.50 \%$ \\
Hemoptysis & 1 & $1.50 \%$ \\
Pedal edema & 1 & $1.50 \%$ \\
\hline
\end{tabular}

The most frequent cause of pleural effusion was tuberculosis in $38 \%$ of patients, followed by parapneumonic effusion $(28.5 \%)$, malignant pleural effusion $(22.2 \%)$. Three patients had chylothorax, two patients had pancreatic pleural effusion and the diagnosis was unknown in 2 patients [Figure 3]. In a similar study done by Adeoye et al., ${ }^{[17]}$ the most common cause of pleural effusion was tuberculosis in $32.9 \%$ of patients, followed by malignancy (29.1\%) and pneumonia (15\%). Mbata Godwin et al. ${ }^{[15]}$ in a 5-year retrospective study, the most common etiology was tuberculosis in $42.2 \%$ of patients followed by parapneumonic effusion in $14.07 \%$ of patients. A study from Qatar by Khan et al. ${ }^{[11]}$ showed that the most common cause of pleural effusion was tuberculosis in $32.5 \%$ of patients, followed by parapneumonic effusion, malignant effusion, and cardiac failure in $19 \%, 15.5 \%, 13 \%$, respectively.

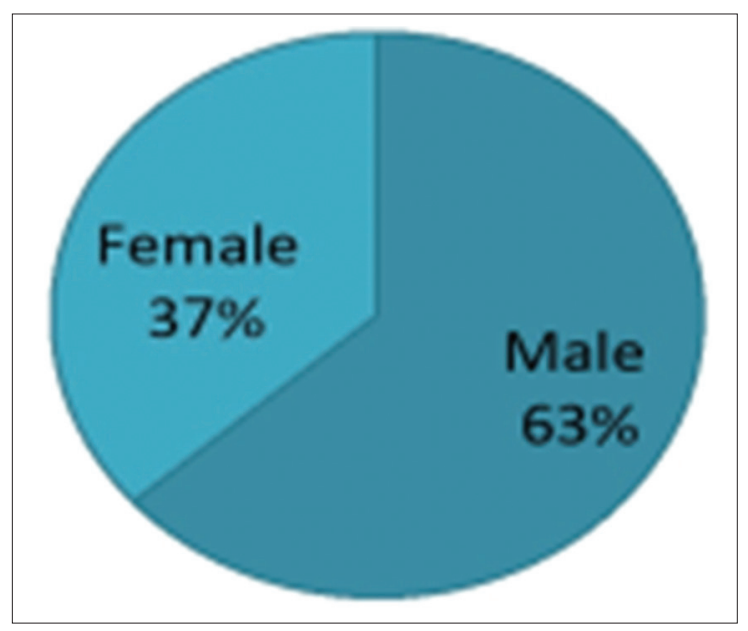

Figure 1: Gender distribution of the study population

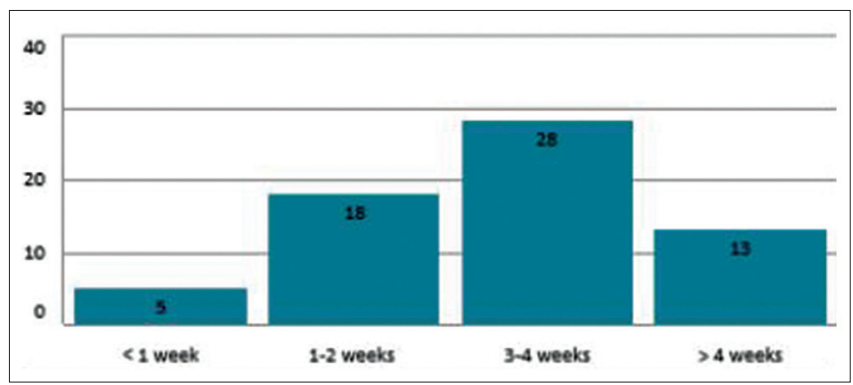

Figure 2: Duration of symptoms of the study population

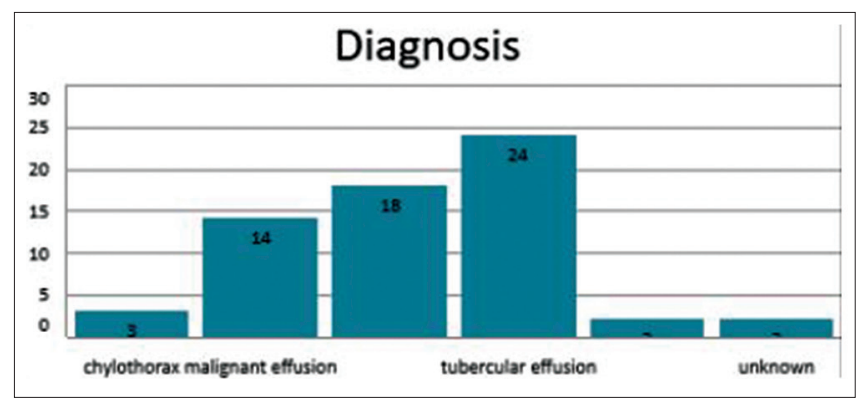

Figure 3: Etiology of pleural effusion of the study population 
Reddy, et al:: Clinical and etiological profile of an exudative pleural effusion

In $1.5 \%$ of cases, the etiology of pleural effusion was not found. Al-Alusi ${ }^{[14]}$ included 100 patients in their study which showed that the most frequent cause of pleural effusion was tuberculosis, which occurred in $38 \%$ of patients and malignant disease accounted for $34 \%$ of cases.

In our study, mean \pm SD of age in tuberculous, parapneumonic, and malignant pleural effusion was $51.8 \pm 16.5,45.7 \pm 21.6$, and $44.6 \pm 19.9$, respectively. Mean \pm SD of duration of symptoms was $4.22 \pm 3.2,3.59 \pm 3.2$, and $3.94 \pm 2.3$ weeks in tuberculous, parapneumonic, and malignant pleural effusions, respectively. Similar study by the Desalew et al. ${ }^{[16]}$ showed that the mean duration of the clinical symptoms was 66 days prior to hospital visit with a range of 3-365 days which was high when compared to our study, this may be due to better availability of health-care facilities in India compared to Ethiopia where above study was conducted. Pleural fluid glucose ranged between 3 and $290 \mathrm{mg} / \mathrm{dl}$ and mean $\pm \mathrm{SD}$ value was $67.7 \pm 48.2$. Mean $\pm \mathrm{SD}$ of glucose in tuberculous group was $82.7 \pm 34.3$, in malignant group, it was $72.7 \pm 43.6$. In parapneumonic effusion group, it was $31.2 \pm 24.6$. Pleural fluid lymphocyte $(\%)$ ranged from 0 to $100 \%$. Mean \pm SD value of study population was $47.9 \pm 33.3(\%)$. Mean \pm SD of lymphocyte $(\%)$ of tuberculous, parapneumonic, and malignant pleural effusion was $74.5 \pm 23.7,43.9 \pm 29.4$, and $16.3 \pm 14.9(\%)$, respectively [Table 3 ].

In our study, ADA value ranged between 1.7 and 130U/L. Mean \pm SDADA value of the study population was $45.3 \pm 28.1$. Mean $\pm \mathrm{SD}$ of ADA values in tuberculous, parapneumonic, and malignant pleural effusion was $54.5 \pm 16.8,65.2 \pm 30.7$, and $18.2 \pm 11.0$, respectively [Table 3]. Gupta et al. ${ }^{[18]}$ in their study showed that in tuberculous group the mean $\pm \mathrm{SD}$ ADA was $67.34 \pm 22.85$, while in nontuberculous group, it was $18.60 \pm 9.12$. In our study, the mean ADA value in parapneumonic effusion group was higher than tuberculous effusion group and this can be explained by the fact that differentiation between parapneumonic effusions and empyema was not done leading to high ADA levels. In a similar study by Valdés et al. ${ }^{[19]}$ the mean ADA concentration in the patients with tuberculous effusion was $111.1 \mathrm{U} / \mathrm{I}$ and in empyema it was $139.7 \mathrm{U} / \mathrm{I}$. Hence, pleural ADA carries high diagnostic importance for tuberculosis and it should be done wherever possible. ADA levels were elevated not only in lymphocytic effusions but also in neutrophilic effusions. Extremely high ADA levels were seen in lymphoma and empyema. ${ }^{[20]}$ Shenoy et al. ${ }^{[21]}$ conducted a retrospective study on patients who were diagnosed to have tuberculous pleural effusion and empyema of nontubercular origin. Among 46 patients, 25 patients with tuberculous pleural effusion and 21 patients with empyema were diagnosed, respectively. Pleural fluid ADA levels among tuberculous pleural effusion and empyema were $109.38 \pm 53.83 \mathrm{U} / \mathrm{L}$ and $141.20 \pm 71.69 \mathrm{U} / \mathrm{L}$ respectively. They concluded that apart from ADA, other parameters like lymphocyte to neutrophil ratio and glucose levels should be used to diagnose tubercular pleural effusion.

In our study, ADA level in all 24 patients of tuberculous pleural effusion was above diagnostic cut-off (30 U/L), whereas out of 14 malignant effusion patients, only two patients had above the cut-off value and 12 patients had ADA value below the cut-off (30 U/L) and it was statistically significant $(P<0.05)$ [Table 4 ]. Helmy et al. ${ }^{[22]}$ did a retrospective study with 30 patients. There was a statistically significant difference according to the levels of pleural fluid ADA between tuberculous pleural effusion and malignant pleural effusion groups and confirmed that ADA is a very useful parameter for the differential diagnosis of tuberculous and malignant pleural effusion. In review article by Goto et al., ${ }^{[23]}$ the sensitivity of ADA reported in ranged from $47.1 \%$ to $100 \%$ and the specificity from $50 \%$ to $100 \%$. In our study, ADA (cut-off $30 \mathrm{U} / \mathrm{L}$ ) had 92\% sensitivity, 100\% specificity and positive and negative predictive values were 1.00 and 0.85 for diagnosis of tuberculosis. In a similar study by Bandrés Gimeno et al., ${ }^{[24]}$ the cut-off value of ADA $>23 \mathrm{U} / \mathrm{L}$ had sensitivity, specificity, positive, and negative predictive values were $96 \%, 100 \%, 1.0 \%$, and $0.94 \%$, respectively, for differentiating tuberculous pleuritis or neoplasia with lymphocytic exudate. Therefore, ADA value is sensitive and specific test for the diagnosis of tuberculous pleurisy. The results of ADA levels should be interpreted in parallel with clinical findings and other pleural fluid parameters such as lymphocyte to polymorphs ratio, glucose levels, and cytopathology to differentiate between tuberculous effusion and parapneumonic effusion.

Table 3: Pleural fluid characteristics of major types of effusions

\begin{tabular}{|c|c|c|c|c|}
\hline & Tuberculous effusion (24) & Malignant effusion (14) & Parapneumonic effusion (18) & $P$ \\
\hline Male & $15(62.5 \%)$ & $8(57 \%)$ & $11(61 \%)$ & 0.950 \\
\hline Female & $9(37.5 \%)$ & $6(45 \%)$ & $7(39 \%)$ & \\
\hline Age & $51.8 \pm 16.53$ & $45.7 \pm 21.6$ & $44.6 \pm 19.29$ & 0.420 \\
\hline Symptoms duration (weeks) & $4.22 \pm 3.26$ & $3.59 \pm 3.38$ & $3.94 \pm 2.26$ & 0.819 \\
\hline TLC & $1442.8 \pm 1144$ & $425.3 \pm 304.2$ & $3172.2 \pm 2654.5$ & $0.00004 *$ \\
\hline Lymphocytes (\%) & $75.58 \pm 23.7$ & $49.3 \pm 29.4$ & $16.39 \pm 14.8$ & $0.0000^{*}$ \\
\hline $\mathrm{LDH}$ & $1363.5 \pm 1083$ & $1002.9 \pm 949.5$ & $2309.6 \pm 2018$ & $0.025^{*}$ \\
\hline Amylase & $61.63 \pm 54.9$ & $177.2 \pm 156.4$ & $58.5 \pm 38.6$ & $0.0085^{*}$ \\
\hline ADA & $54.50 \pm 16.8$ & $18.2 \pm 11.0$ & $65.2 \pm 30.2$ & $0.0000^{*}$ \\
\hline
\end{tabular}


Reddy, et al:: Clinical and etiological profile of an exudative pleural effusion

\begin{tabular}{|c|c|c|c|c|}
\hline \multicolumn{5}{|c|}{$\begin{array}{l}\text { Table 4: Pleural fluid Adenosine deaminase (ADA) levels } \\
\text { with their significance }\end{array}$} \\
\hline Group & ADA levels & Frequency & Mean \pm SD & $P$ \\
\hline \multirow{2}{*}{$\begin{array}{l}\text { Tuberculous } \\
\text { effusion }(n=24)\end{array}$} & $<30$ & $0(0 \%)$ & $54.50 \pm 16.8$ & $<0.05^{*}$ \\
\hline & $>30$ & $24(100 \%)$ & & \\
\hline \multirow{2}{*}{$\begin{array}{l}\text { Malignant } \\
\text { effusion }(n=14)\end{array}$} & $<30$ & $12(88 \%)$ & $18.2 \pm 11.0$ & \\
\hline & $>30$ & $2(12 \%)$ & & \\
\hline
\end{tabular}

\section{Conclusions}

Pleural effusion is common clinical entity in day-to-day practice in India. Tuberculosis is one of the common causes of exudative effusions along with parapneumonic effusions and malignancy. Pleural fluid ADA levels highly sensitive with good specificity for the diagnosis of etiology of tubercular effusions. However, in view of high levels of ADA in parapneumonic effusions also, other measures such as clinical evaluation, lymphocyte to neutrophil ratio, and glucose levels are necessary to separate both these entities.

\section{Financial support and sponsorship}

Nil.

\section{Conflicts of interest}

There are no conflicts of interest.

\section{RefEREnCES}

1. Diaz-Guzman E, Dweik RA. Diagnosis and management of pleural effusions: A practical approach. Compr Ther 2007;33:237-46.

2. Noppen M. Normal volume and cellular contents of pleural fluid. Curr Opin Pulm Med 2001;7:180-2.

3. Sahn SA. The differential diagnosis of pleural effusions. West J Med 1982;137:99-108.

4. Light RW, Macgregor MI, Luchsinger PC, Ball WC Jr. Pleural effusions: The diagnostic separation of transudates and exudates. Ann Intern Med 1972;77:507-13.

5. Chetty KG. Transudative pleural effusions. Clin Chest Med 1985;6:49-54.

6. Collins TR, Sahn SA. Thoracocentesis. Clinical value, complications, technical problems, and patient experience. Chest 1987;91:817-22.

7. Froudarakis ME. Diagnostic work-up of pleural effusions.Respiration. 2008;75:4-13.

8. Lau JS, Yuen CK, Mok KL, Yan WW, Kan PG. Visualization of the inferoposterior thoracic wall (VIP) and boomerang signs-novel sonographic signs of right pleural effusion. Am J Emerg Med 2018;36:1134-8.

9. Storey DD, Dines DE, Coles DT. Pleural effusion. A diagnostic dilemma. JAMA 1976;236:2183-6.

10. Light RW. Diagnostic principles in pleural disease. Eur Respir J 1997;10:476-81.

11. Khan FY, Alsamawi M, Yasin M, Ibrahim AS, Hamza M, Lingawi M, et al. Etiology of pleural effusion among adults in the state of Qatar: A l-year hospital-based study. East Mediterr Health J 2011;17:611-8.

12. Shashikant A, Archana G. A study of clincoetiological profile of patients with pleural effusion. J Dent Med Sci IOSR 2017; 16:23-7.

13. Raghavan S, Jayachandran R, Mosses S. Clinical and etiological profile of patients with pleural effusion in a tertiary care centre. JMSCR 2017;5:23553-8.

14. Al-Alusi F. Pleural effusion in Iraq: A prospective study of 100 cases. Thorax 1986;41:492-3.

15. Mbata Godwin C, Ajuonuma Benneth C, Ofondu Eugenia O, Aguwa Emmanuel N. Pleural effusion: Aetiology, clinical presentation and mortality outcome in a tertiary health institution in Eastern Nigeria - A five year retrospective study. J AIDS Clin Res 2015;6:2.

16. Desalew M, Amanuel A, Addis A, Zewdu H, Jemal A. Pleural effusion: Presentation causes and treatment outcome in a resource limited area, Ethiopia. Health 2012;4:15-9.

17. Adeoye PO, Johnson WR, Desalu OO, Ofoegbu CP, Fawibe AE, Salami AK, et al. Etiology, clinical characteristics, and management of pleural effusion in Ilorin, Nigeria. Niger Med J 2017;58:76-80.

18. Gupta BK, Bharat V, Bandyopadhyay D. Role of adenosine deaminase estimation in differentiation of tuberculous and non-tuberculous exudative pleural effusions. J Clin Med Res 2010;2:79-84.

19. Valdés L, Alvarez D, San José E, Juanatey JR, Pose A, Valle JM, et al. Value of adenosine deaminase in the diagnosis of tuberculous pleural effusions in young patients in a region of high prevalence of tuberculosis. Thorax 1995;50:600-3.

20. Porcel JM, Esquerda A, Bielsa S. Diagnostic performance of adenosine deaminase activity in pleural fluid: A single-center experience with over 2100 consecutive patients. Eur J Intern Med 2010;21:419-23.

21. Shenoy V, Singh K, Prabhu K, Datta P, Varashree BS. Evaluation of usefulness of pleural fluid adenosine deaminase in diagnosing tuberculous pleural effusion from empyema. Asian Pac J Trop Dis 2014;4:S411-4.

22. Helmy NA, Eissa SA, Masoud HH, Assem F. Elessawy C, Ahmed RI. Diagnostic value of adenosine deaminase in tuberculous and malignant pleural effusion. Egypt J Chest Dis Tuberc 2012;61:413-7.

23. Goto M, Noguchi Y, Koyama H, Hira K, Shimbo T, Fukui T. Diagnostic value of adenosine deaminase in tuberculous pleural effusion: A meta-analysis. Ann Clin Biochem 2003;40:374-81.

24. Bandrés Gimeno R, Abal Arca J, Blanco Pérez J, Gómez-González MC, Cueto Baelo M, Piñeiro Amigo L, et al. Adenosine deaminase activity in the pleural effusion. A study of 64 cases. Arch Bronconeumol 1994;30:8-11. 